\title{
Active Microring Resonator Devices in Silicon-on-Insulator
}

\author{
Richard Soref \\ Air Force Research Laboratory, Electromagnetic Technology Division, Hanscom AFB, MA 01731 \\ Telephone: 781-377-2380 Fax: 781-377-6948 \\ richard.soref@hanscom.af.mil
}

\begin{abstract}
Recent results from several laboratories are surveyed. The topics include SOIbased ultrafast electrooptical modulators, $\mathrm{N} \times \mathrm{N}$ routing switches, tunable filters-andadd/drops, Raman lasers and amplifiers, electrically pumped group IV lasers, optically pumped $\mathrm{Er}_{\mathrm{SiO}}$-overclad slotted rings, and a variety of nonlinear optical devices.
\end{abstract}

OCIS codes: (130.0130) Integrated Optics; (250.0250) Optoelectronics; (130.1750) Components

1. Introduction Microphotonic and nanophotonic components in SOI (or in SGOI or GOI) are key "enablers" for the next generation of Si-based waveguided photonic networks and opto-electronic integrated circuits (OEICs). Microring and microdisk resonators are advantageous microphotonic components because they can be interconnected densely on a chip and use minimal "real estate," allowing high functionality at low cost. Active rings offer versatility in applications, efficiency and low-power onchip actuation. The term "active" includes thermooptic (TO) electrooptic (EO) and opto-optical devices (those using nonlinear optical interactions). This talk will survey the recent results obtained at several laboratories on active microring resonator devices. Generally, the $\mathrm{SiO}_{2}$ lower cladding in SOI, SGOI and GOI maintains the high $\mathrm{Q}$ of the resonators; whereas, without $\mathrm{SiO}_{2}$, the resulting suspended $\mathrm{Si}$ membrane is best for $2 \mathrm{D}$ photonic-crystal resonators analogous to the disks. In addition to $2 \mathrm{D}$ rings and disks, $3 \mathrm{D}$ silicon microsphere resonators have achieved visibility lately [1].

2. Trimmable Optical Filters. Empirically, the resonators rarely "work as fabricated." Electromagnetic modeling software is not (yet) good enough to predict the resonances of a 3D device having very specific dimensions. So, in practice, the microring spectral filtering characteristic, as fabricated, does not match the design specifications. That is why trimming or tuning of the resonator(s) has become essential. Polymeric loading on the Si waveguide - controlled photo-oxidation of polysilane [2]-- is a good way to trim the resonator permanently and stably. Trimming is an essential part of Luxtera's WDM [3]. Today, localized heating of the silicon waveguide (a TO index change) is the most explored and effective means of tuning the resonator, although electrooptical tuning of the ring (steady carrier injection or depletion) will be online soon.

3. Tunable Filters and Add/Drop Multiplexers. TO trimming-and-tuning has facilitated the worldrecord $1 \mathrm{GHz}$ bandpass of a multi ring/MZI filter that has $5 \mathrm{GHz}$ tunability [4]. The TO-activated polymeric two-ring reconfigurable add/drop multiplexer of Yamagata [5] could be realized easily in vertically stacked double-SOI containing two Si buses and two TO-tunable Si microrings, allowing significant WDM tuning.

4. 2 x 2 and $\mathbf{N} \times \mathbf{N}$ Optical Routing Switches. Stephen Emelett and I wrote several papers $[6,7,8]$ on dual-microring switches (fixed-ring devices and floating-ring devices) that are readily cascaded into $\mathrm{N} \mathrm{x} \mathrm{N}$ crossbar-matrix crossconnects [9] or permutation-matrix network-routing switches. The preferred embodiments use carrier injection-or-depletion in both rings, obtained via lateral PIN contacts [6] or by a vertical MOS structure $[10,11]$. The $1 \mathrm{x} 1$ version of the switch is an intensity modulator whose transfer characteristic can be linear over four decades of $\mathrm{P}_{\text {out }} v s \Delta \mathrm{n}$. The linearity arises because, for paired rings, the skirts of the box-like spectral response can be engineered to be steep and straight. EO logic [12] is another switch application. In an SOI chip, several waveguided EO logic elements (LEs) are interconnected, and each LE is comprised of several $1 \times 2$ and $2 \times 1$ EO microring switches, plus four $1 \times 1$ microring EO modulators. In operation, two phase-coherent "digital" optical data streams A and B are coupled into the LE (light beam on = binary 1; light beam off = binary 0 ) and the LE performs any one of 16 possible Boolean logic functions on $\mathrm{A}$ and $\mathrm{B}$. 
5. Ultrafast Electrooptical Modulators Michal Lipson's group is the pioneer in this area [13] and their recent results with the lateral-PIN-diode waveguided ring are: $25 \mathrm{ps}$ rise time, $>5 \mathrm{GHz}$ bandwidth and 0.3 $\mathrm{V}$ for $\mathrm{min} / \mathrm{max}$ optical swing [14]. A very significant development was reported by Luxtera and its team members who have attained $10 \mathrm{~Gb} / \mathrm{s}$ modulation in a carrier-depletion Si microring modulator [15,16,17]. This fast, efficient device uses a reverse-biased lateral PN junction within the Si ring, and the manufacturing is fully compatible with a 130-nm CMOS SOI production facility (a high-volume Fab).

6. Optically Controlled Optical Modulators Nonlinear optical (NLO) modeling and simulation predict $94 \mathrm{GHz}$ modulation of a weak optical signal by a strong $1550 \mathrm{~nm}$ pump in a Si slotted ring containing silicon nano-crystals [18]. The speed of pump-and-probe modulation via two-photon absorption is limited by free-carrier lifetime in the range of 100 to $400 \mathrm{ps}$ [19].

7. Slotted Microring EO Modulators and Light Emitters We know from the experiments of Polman and colleagues that $\mathrm{Er}$ doping of an $\mathrm{Si}$-based $\mathrm{SiO}_{2}$ microring will give optically pumped lasing at cryogenic temperatures [20]. Taking this a step further, if this $\mathrm{Er}^{-\mathrm{SiO}_{2}}$ material is inserted into the 60-nm-wide slot in a waveguided, laterally contacted silicon microring, then the carrier transport through this oxide by highfield Fowler-Nordheim tunneling will give strong electroluminescence, perhaps lasing $[21,22]$

8. Laser Diode Candidates I have proposed an electrically pumped room-temperature microring laser in vertically 3D-integrated SOI/SOI or SGOI/SOI for $1.3-1.6 \mu \mathrm{m}$ laser emission [23]. Lateral PIN pumping of the ring is proposed, and a key feature is that the waveguided ring consists of nanostructured $\mathrm{Si}$ or SiGe to provide more optical gain [24] than available from bulk crystal Si or SiGe. As shown in Fig. 5 of [23], the active-ring region can be a lateral superlattice of 60 -nm-diam pores [24].

9. Possible Raman Lasers. Bahram Jalali in an unpublished 2006 paper has proposed an optically pumped Raman laser (or amplifier) in the form of an SOI microring coupled vertically to a linear SOI strip wavguide, a geometry quite similar to that of my electrically pumped laser. He has shown experimentally that an SOI microring "photonic layer" can be buried beneath a working CMOS transistor as part of a subterranean OEIC [25].

10. Nonlinear Optical Devices The NLO interactions that are currently exploited in SOI microring devices include optical rectification, the Pockel's effect and detection [26], all-optical modulation, twophoton absorption, all-optical wavelength conversion, optical bistability, four-wave mixing, all-optical pump-and-probe switching, pump-and-probe routing of an optical pulse to the drop-or-through port, and all-optical logic gates. (The 3-page limit here prevents me from listing the NLO references).

11. Alternative Non-ring Resonators with Ultrasmall Mode Volume: When a mode volume of less than $(\lambda / n)^{3}$ is wanted, the Fabry-Perot cavity situated in an SOI sub-micron strip waveguide will satisfy this need, as is illustrated in Figs. 3 and 4 of my patent [27] in which the resonator is a point defect within a 1D photonic-crystal reflectors or a Si rectangle between Bragg-mirror slots. Robinson et al [28] add an in-line slot to the strip to confine the mode within a $10^{-2}(\lambda / 2 \mathrm{n})^{3}$ lower-index region. Other ultrasmall cavities are feasible [29].

Acknowledgement: The author is most grateful to AFROSR/NE (Dr. Gernot Pomrenke) for sponsorship of his inhouse research at AFRL/SNHC.

\section{References:}

1. A. Serpenguzel, "Microphotonic applications of silicon microspheres," Materials Research Society Spring Meeting, paper I8.4, San Francisco, 19 April 2006

2. D. K. Sparacin, J. P. Lock, Ching-yin Hong, K. K. Gleason, L. C. Kimerling, and J. Michel, "Trimming of silicon nitride microring resonators with a polysilane top cladding," ${ }^{\text {nd }}$ IEEE International Conference on Group IV Photonics, Digest pp 117-119, Antwerp, Belgium, 21-23 Sept. 2005

3. C. Gunn, "DARPA EPIC program update: Luxtera's development of a $100 \mathrm{~Gb}$ transceiver using CMOS photonics technology', Government Microcircuit Applications and Critical Technologies Conference, San Diego, CA, 20 Mar 2006.

4. M. S. Rasras, D. M. Gill, S. S. Patel, A. E. White, K.Y. Tu, Y.K. Chen, B. Carothers, A. Pomerene, M. J. Grove, D. Sparacin, J. Michel, M. Beals and L. C. Kimering, "Tunable narrowband optical filter in CMOS", postdeadline paper PDP13, Optical Fiber Conference, Anaheim, CA, 5-10 Mar 2006

5. S. Yamagata, T. Kato and Y. Kokobun, "Non-blocking wavelength channel switch using TO effect of double series-coupled microring resonator," Electronics Letters, 41, 12 May 2005

6. S. J. Emelett and R. A. Soref, "Analysis of dual-microring-resonator cross-connect switches and modulators," Optics Express, 13, no. 20, pp. 7840-7853, 3 October 2005. 
7. S. J. Emelett and R. A. Soref, "Design and simulation of silicon microring optical routing switches," IEEE Journal of Lightwave Technology, 23, pp. 1800-1807, April 2005.

8. R. A. Soref, "Requirements and technology for silicon photonic interconnects," IEEE LEOS 17th annual workshop on interconnections within high-speed digital systems, Santa Fe, NM 17 April 2006.

9. R. A. Soref and B. E. Little, "Proposed N-Wavelength M-Fiber WDM Crossconnect Switch Using Active Microring Resonators", IEEE Photonics Technology Letters, 10, pp 1121-1123 August 1998 10. L. Chao and A. W. Poon, "Active silicon microring resonators using metal-oxide-semiconductor capacitors", $1^{\text {st }}$ IEEE Intl. Conf. on Group IV Photonics, Digest, pp. 19-21, Hong Kong, 29 Sept 2004 11. M. Lipson, "Guiding, modulating and emitting light on silicon-challenges and opportunities", IEEE J. of Lightwave Technology, 23, pp 4222-4238, Dec 2005

12. H. J. Caulfield, R. A. Soref and C. Vikram,"Universal reconfigurable optical logic with silicon-oninsulator resonant structures", Photonics and Nanostructures - Fundamentals and Applications (Elsevier UK), submitted 19 February 2006.

13. Xu, Q., Schmidt, B., Pradhan, S. and Lipson, M., "Micrometre-scale silicon electro-optic modulator ", Nature, 435, pp. 325-327, 19 May 2005.

14. L. C. Kimerling, A. B. Apsel, M. Beals, D. Carothers, Y. Chen, T. Conway, D. Gill, M. Grove, C.

Hong, M. F. Lipson, J. Liu, J. Michel, S. S. Patel, A. T. Pomerene,, M. Rasras, D. K. Sparacin, A. E. White and C. Wong, "Recent advances in CMOS compatible integrated photonics', invited paper 6125-02, SPIE Photonics West, SPIE Proceedings vol. 6125 on Silicon Photonics, San Jose, CA, 25 Jan 2006

15. A. Huang, C. Gunn, G.L. Li, S. Mirsiadi, A. Narasimha and T. Pinguet, "A $10 \mathrm{~Gb} / \mathrm{s}$ photonic modulator and WDM MUX/DEMUX integrated with electronics in $0.13 \mu \mathrm{m}$ SOI CMOS", Proceedings of the IEEE Int'l Solid State Circuits Conf., San Francisco, CA, 5 Feb 2006

16. C. Gunn, "CMOS photonics technology platform", invited paper 6125-01, SPIE Photonics West, SPIE Proceedings vol. 6125 on Silicon Photonics, San Jose, CA, 25 Jan 2006

17. C. Gunn, "CMOS Photonics ${ }^{\mathrm{TM}}$-SOI learns a new trick', invited paper, Proceedings of the 2005 IEEE Int'l SOI Conference, Honolulu, HI, 3 Oct 2005

18. C. A. Barrios, "High performance all-optical silicon microswitch", Electronics Letters, 40, pp 862-863, 8 July 2004.

19. C. Manolatou and M. Lipson, "All-optical silicon modulators based on carrier injection by two-photon absorption”, IEEE J. of Lightwave Technology, 24, pp 1433-1439, Mar 2006

20. T. J. Kippenberg, J. Kalkman, A. Tchebotareva, A. Polman and K. J. Vahala, "Demonstration of Erbium-doped micro-disk laser on silicon", Materials Research Society Spring Meeting, paper I8.1, San Francisco, CA, 19 Apr 2006

21. Barrios, C. A. and Lipson, M., "Electrically driven silicon resonant light emitting device based on slotwaveguide", Optics Express, 13, No. 25, 12 December 2005.

22. O. J. Painter, "SOI with Er:SiOx overcladding: microphotonic design and fabrication for ultra-compact amplifying circuits and low-threshold broadband Si-based lasers," paper I13.1, Materials Research Society Spring Meeting, San Francisco, 20 April 2006.

23. R. A. Soref, "The past, present and future of silicon photonics", (invited) IEEE J. of Selected Topics on Quantum Electronics, special issue on silicon photonics, submitted 3 Nov 2005

24. S. G. Cloutier, C. H. Hsu, P. A. Kossyrev and J. Xu, "Enhancement of radiative recombination in silicon via phonon localization and selection-rule breaking", Nature Materials, 18, pp 841-844, 2006 25. P. Koonath, T. Indukuri and B. Jalali, "Monolithic 3-D Silicon Photonics," IEEE J. of Lightwave Technology, 24, pp. 1796-1804, April 2006

26. T. Baehr-Jones, M. Hochberg, G. Wang, R. Lawson, Y. Liao, P. Sullivan, L. Dalton, A. Jen, and A. Scherer, "Optical modulation and detection in slotted Silicon waveguides," Opt. Express 13, pp. 52165226, 2005

27. R. A. Soref, "Nanometer-scale silicon-on-insulator photonic components"-- U. S. Patent 5,838,870, issued 17 November 1998

28. J. T. Robinson, C. Manolatou, L. Chen and M. Lipson, "Ultrasmall mode volume in dielectric optical microcavities", Phys. Rev. Letters, 95, 143901, 2005

29. A. Gondarenko, S. Preble, J. Robinson, L. Chen, M. Lipson, H. and Lipson,, "Spontaneous emergence of periodical patterns in a biologically-inspired simulation of photonic structures", Physical Review Letters, 96, 143904, 2006 